\title{
High strength steel cold-formed hollow sections: implication of cross-section aspect ratio and slenderness characteristics on flexural behavior
}

\author{
Shady Adib ${ }^{1}$, Ieva Misiunaite ${ }^{2}$ \\ Department of Steel and Composite Structures, Faculty of Civil Engineering, \\ Vilnius Gediminas Technical University, Vilnius, Lithuania \\ E-mail: ${ }^{1}$ shady-essam-adly.adib@stud.vgtu.lt (corresponding author)
}

\begin{abstract}
Cold-formed tubular sections are widely applicated for a variety of structural solutions, primarily due to their advantageous structural properties, inherent aesthetic characteristics and ease of prefabrication and mass production. High strength steels (HSS) are attaining growing attention from structural engineers and researchers due to their potential on the design of lightweight and more economic structures. In combination with cold-formed tubular sections HSS might serve as improvement on structural efficiency as well as solution for structural problems when usage of normal steel is limited due to insufficient strength. However, innovative structural solutions are often faced problems related with absence of appropriate design procedures. In most of the design codes cross-section design is performed following the traditional classification procedure based on the slenderness of the individual constituents without respect to their interaction. Moreover, tubular sections are generally treated in the same manner without respect to their formation route, embedding an elastic-perfectly plastic material model, without reference to the cold-formed sections increased strength and reduced ductility over the flat material. This paper reports on the numerical study of cold-formed HSS tubular beams deformation response, with a focus on the effect of cross-section constituent's interaction and strength enhancement influence on the cross-section slenderness. Finite element (FE) models were first developed and validated against existing test results. Upon validation against the experimental results, parametric studies were carried out to expand the available flexural response data over a range of cross-section aspect ratio, cross-section slenderness and steel grades. The obtained numerical results were used to assess the suitability of the current design codes cross-sections classification for cold-formed HSS tubular beams.
\end{abstract}

Keywords: High strength steel (HSS), slenderness limits, strength enhancement, cross-section aspect ratio, cold-formed hollow sections

\section{Introduction}

Within the range of steel structures design standards (EN 1993-1-1, ANSI/AISC 360-10, AS 4100), high strength steel (HSS) is defined as steel with yielding strength $\geq 460 \mathrm{MPa}$. It may serve as an alternative for the engineers to build and design more efficient, safe and economic structures. Within the years, there is an increasing demand for high strength steel within the construction. The merits of HSS rest on the higher yielding strength of the materials leading to the smaller sectional dimensions of the members and reduced self-weight of the structures than counterparts of Normal Strength Steel (NSS). However, as any of the novelty the usage of HSS for the design of the structures refers to the lack of knowledge on the behaviour and appropriate design methods. Within the range of cross-sections used for the design of steel structures, hollow sections are taking the leading part as the solution for constructing the lightweight structures. The production of hollow sections usually is following either hot-rolling or cold-forming routing. Hot rolling may be a mill process that involves rolling the steel at a high temperature, which is above the steel's re-crystallization temperature. once steel is above the re-crystallization temperature, it may be formed and shaped simply, and therefore the steel may be created in a lot of larger sizes. Cold rolled steel is essentially hot rolled steel that has had additional process. The steel is processed further in cold reduction mills, wherever the material is cooled (at room temperature) followed by annealing and/or tempers rolling. This method can produce steel with closer dimensional tolerances and a wider range of surface finishes. Cold formed steel undergoes plastic deformation throughout forming. Plastic deformation causes cold-working of the material, resulting in enhanced strength, however a corresponding loss of ductility. Non-homogeneity of material properties and variation in hardness around the section typically arise because of the uneven levels of plastic deformation experienced during forming; the corner regions of cold-formed 
sections, specially, undergo high levels of cold-work, and larger corner radii are specified in EN 10219-2 to avert corner cracking. also associated with non-uniform plastic deformation is the formation of residual stresses in coldformed structural sections, these generally appear as through-thickness bending residual stresses. There are lots of researches investigation flexural response of high strength steel sections however, the flexural response and analysis and design of high strength steel cold-formed tubular sections is still under investigation. An experimental investigation of cold-formed high strength steel tubular beams flexural response with high strength steel of 700, 900, $1100 \mathrm{MPa}$ were performed (Ma, Chan, \& Young, 2016). Results showed that low material ductility reduces the available rotation capacities of the sections and subsequently the class 1 limit is no longer applicable for HSS tubular sections. The plastic slenderness limit and yield slenderness limit were found to be conservative for the HSS tubular sections. A numerical investigation on cold-formed high strength steel tubular sections were conducted (Ma, Chan, Young, 2017). The analysis showed that the method was accurate and reliable in predicting the ultimate capacities for cold-formed high strength steel SHS and RHS beams. Xiang Yun and Leroy Gardner wanted to extend the Continuous strength method (CSM) to the design of cold-formed steel non-slender tubular cross-sections subjected to compression, bending and combined loading, and to verify the proposals through comparisons with existing test data from the literature and finite element results generated in the same paper. It was shown that the CSM offers more accurate mean resistance predictions and less scatter for cold-formed steel cross-sections under compression, bending and combined loading compared to the codified design methods (Yung \& Gardner, 2018). It can be seen from the previous researches that there is no much attention on the influence of strength enhancement of cross-section slenderness and cross section aspect ratio on classification of the cross-section and its lateral deformation response. In this paper, numerical study of cold-formed HSS tubular beams deformation response is performed, with a focus on influence of the cross-section slenderness and aspect ratio between web and flange. Four point bending test were performed using two different cross-sections and steel grades (700 and $900 \mathrm{MPa}$ ). Finite element (FE) twenty models were developed and validated against existing experimental results. Parametric studies were carried out in order to get more results for flexural response data using a wide range of cross section aspect ratio, cross section slenderness and steel grades. Based on the numerical results, the suitability of the current design codes cross-section classification for cold-formed HSS tubular section are carried out. The obtained numerical results are used to perform relation between maximum lateral displacement of the cross section against the load.

\section{Experimental program}

An experimental programme on the HSS beams with the grades S700 and S900 square hollow section (SHS) profiles was carried out at the Laboratory of Innovative Building Structures of Vilnius Gediminas Technical University. The program included material tests and in-plain bending tests on a total of four SHS beams loaded in four-points bending configuration up to failure load. The results of the experimental investigations were used for the numerical simulations and validation of the finite element models (FEM). The test specimens were made of hot-rolled material turned into quadratic shape by the cold-formed production routing. The flat tensile coupons were extracted from each of the sections for the material test. The obtained stress-strain curves were used in the numerical simulations of the test specimens. Two groups of the beam's specimens were tested. The first group was comprised of the SHS with the dimensions $80 \mathrm{X} 80 \mathrm{X} 3 \mathrm{~mm}$ for web, flange and thickness, respectively and the steel grade S700. The beam's sections of the second group had dimensions of 100X100X4 mm for web, flange and thickness, respectively and the steel grade S900.

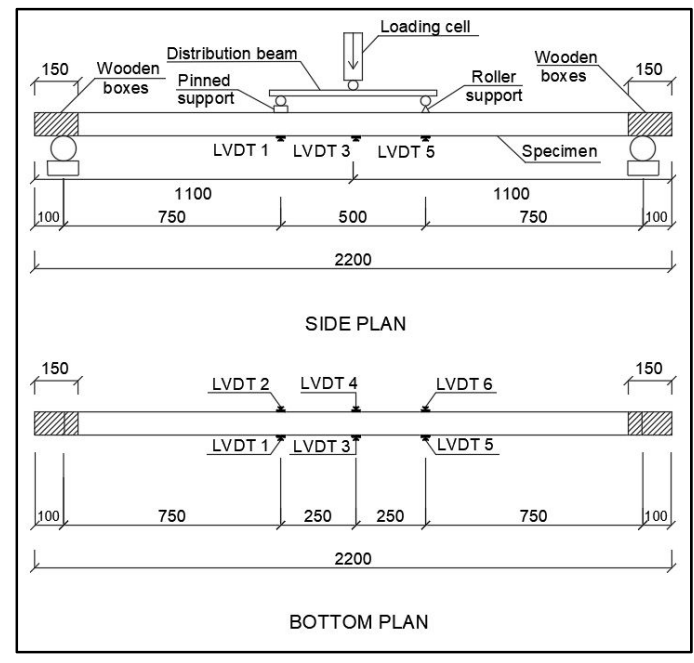

(a) Loading scheme

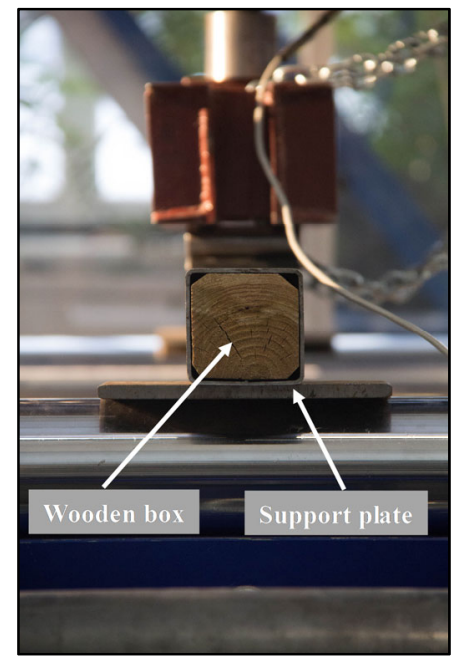

(b) Support arrangement

Figure 1. Four - point bending test apparatus 
The test setup for all beam specimens was constructed in the same way as presented in Figure 1 . The beams of the total length of $2200 \mathrm{~mm}$, had equal overhangs at each end of $100 \mathrm{~mm}$, making the span of the beam equal to 2000 . The bending span of the beams was $500 \mathrm{~mm}$, leaving the equal shear spans of 750 to ensure that section bending capacity would be reached before hear failure occurs (see Figure 1). Each end of the specimen was restrained with the piece of wood to prevent section web crippling. The beam sections at the loading points by means of the pinned and roller supports of the distribution beam were left unrestricted (see Figure 1) to obtain local deformations of the profile. Linear variable displacement transducers (LVDT1-LVDT6) were placed by pears (see Figure 1). The measurements of LVDT were used to obtain vertical displacements in the moment span of the beam. A load cell was used to measure the applied load. All results from LVDT and the load cell were collected and recorded by an ALMEMO 2890-9 data logger. The obtained load-displacement responses and character of the failure mode observed during the test were used to validated numerical simulations.

\section{Numerical investigation}

\section{Numerical model}

The numerical investigation was performed to obtain the pool of data for parametric analysis. It was carried-out reflecting the experimental setup presented in Figure 1 with the following assumption:

- A higher order 3-D solid elements, which exhibit quadratic displacement behaviour were used. These elements are defined by 20 nodes having three degrees of freedom per node. FE support plasticity, stress stiffening, large deflection, and large strain capabilities.

- A regular mesh with the average size of $20 \mathrm{~mm}$ was used.

- To simulate the failure mode observed during the test, the refined mesh was used for the region of the beam at the loading point $\mathrm{P}$ with rough contact (see Figure 2).

- A mesh convergence study was carried-out to establish a sufficiently refined mesh size and an element size of $10 \mathrm{~mm}$ was found to be suitable to capture local failure mode (see Figure 3).

- The rest of the model meshing shape was found to be with rectangular shape for each meshing element due to changing in meshing size from $20 \mathrm{~mm}$ to $10 \mathrm{~mm}$.

-Following the requirements of EN 1993-5 Annex C (EN 1993-5 2006) the nominal geometric properties were incorporated in FE model.

- The test material multilinear stress-strain curves were employed in the FE model in the form of true stressstrain response as recommended in EN 1993-5 Annex C (EN 1993-5 2006).

- The boundary conditions were selected to simulate the experimental set-up and reflect simply supported beam (see Figure 2). At one end of the bottom flange all the displacements were linearly restrained, while at the other end the vertical and lateral displacements were linearly restrained and the longitudinal displacement was set to free transition.

- The loading conditions were simulated as the pressure loads P distributed on the bearing plates of the supports of the distribution beam (see Figure 1).

- To simulate different support conditions of the distribution beam two different contacts between bearing plates and profile were created. The bonded and rough contact were chosen to simulate pinned and roller supports of the distribution beam, respectively.

- The load was applied incrementally with $1 \mathrm{kN}$ load step.

- The loading history embedded both loading and unloading paths to obtain required data for calculations of rotation capacity.

The numerical investigation FE model is presented in Figure 2. The numerical analysis employed general purpose finite element software ANSYS Workbench 18.

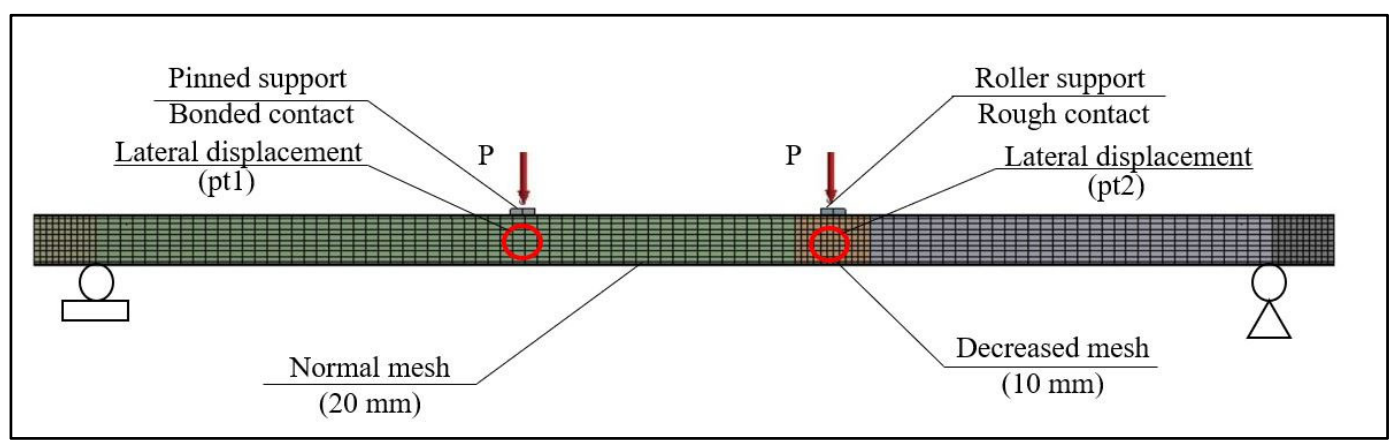

Figure 2. Numerical setup of the model using ANSYS workbench 


\section{Numerical results and validations}

All the test specimens experienced similar failure mode observed visually as asymmetric local buckling of the profile under the loading point $P$ with rough contact (see Figure 2) by means of roller support of distribution beam (see Figure 1). The validation of the FE model was performed in two attempts. First the comparison of the failure mode and ultimate bending moment was performed using the representative test beam with the cross-section $80 x 80 \times 3$ and the steel grade S700 was used. Figure 3a presents the asymmetric local failure observed in the bending span of the test beam in the form of lateral displacement of related FE model. Figures $3 b$ and $3 c$ show the comparison of the local deformations in the failure zone of the test beam at the ultimate bending moment. It can be seen from Figures $3 \mathrm{~b}$ and $3 c$ that the numerical failure mode closely reflects the experimental failure. As can be seen in the Figures $3 b$ and $3 c$ there is no difference in experimentally and numerically obtained values of ultimate bending moments. With the second attempt the FE model validation was based on the comparison of the obtained load-displacement response presented in Figure 4. There was observed no significant difference between the measurements of the LVDT pairs identified in Figure 1. Thus, experimental load-displacement responses in Figure 4 are presented for the respective LVDT pairs at the related loading points and mid-span of the beam. Figure 4a shows that the difference between experimental and numerical load-displacement response obtained at the mid-span of S700 grade beam is negligible in the linear behavior part and is less than $2 \%$ in the nonlinear part. Similarly, the difference between the experimental and numerical loaddisplacement response obtained at the loading point for the same steel grade has the same percentages for linear and nonlinear behaviour part. Figure $4 \mathrm{~b}$ shows that the difference between experimental and numerical load-displacement response obtained at the mid-span of S900 grade beam is negligible in the linear and nonlinear behavior parts as the difference is less than $1 \%$. However, the differences between experimental and numerical load-displacement response obtained at loading point of the same steel grade are less than $1 \%$ in linear part and $2 \%$ in nonlinear part. Figures 3 and 4 show that FE models closely predict the local beam failure at the ultimate moment and load-displacement response at all considered points.

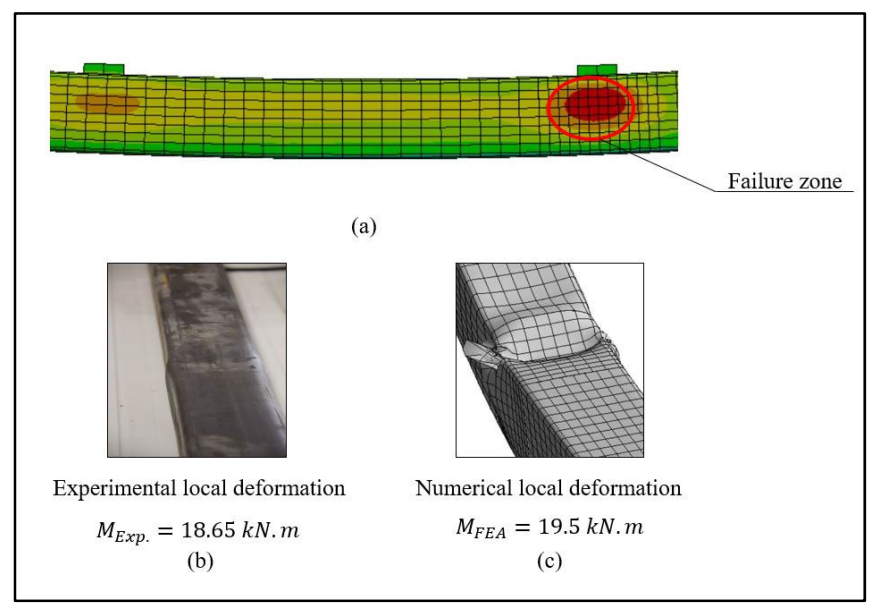

Figure 3. Failure mode of numerical analysis against experimental failures for all models

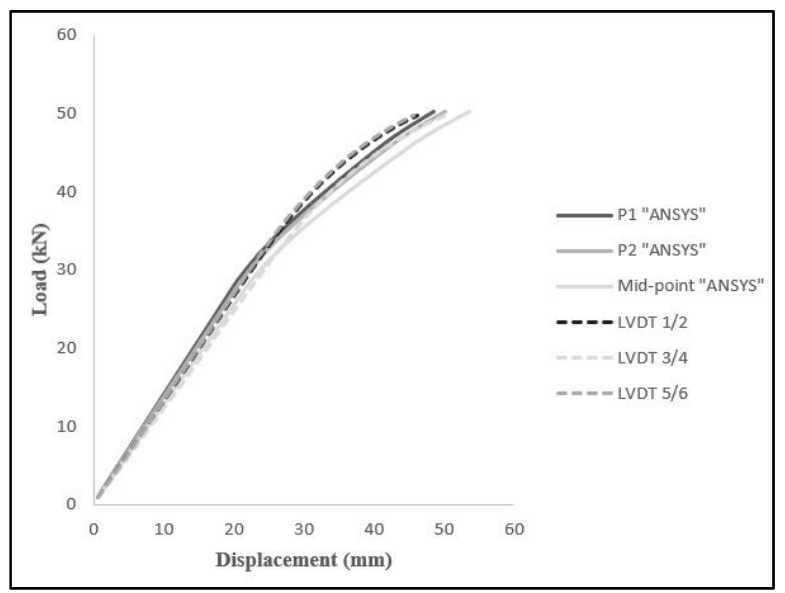

(a) Load - Displacement curve - HSS-S700

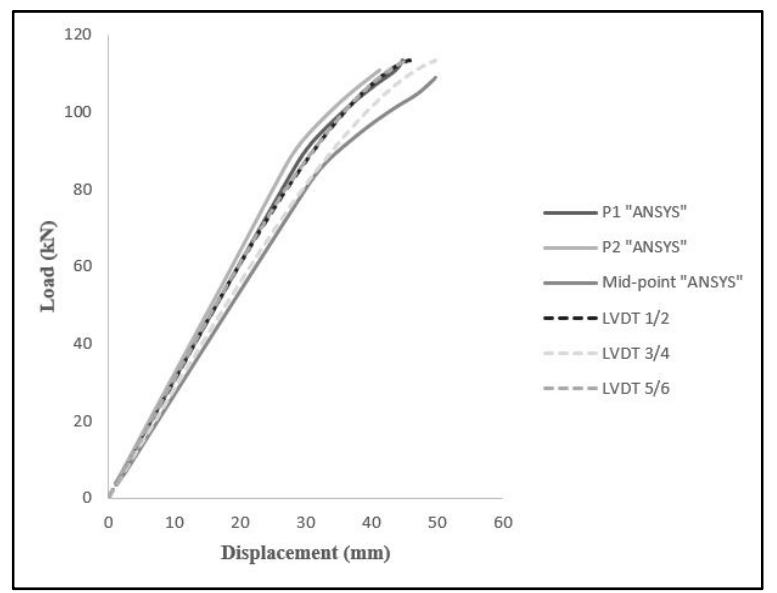

(b) Load - Displacement curve - HSS-S900

Figure 4. Load - Displacement relationship for numerical results against experimental transducers 


\section{Parametric study}

Upon validation against the experimental results, parametric studies were carried out to expand the available flexural response data over a range of cross-section aspect ratio and cross-section slenderness. The assessment is carried out based on standard limitation of European code (EN 1993 1-1), American National Standard (ANSI/AISC 36010) and Australian Standard (AS 4100). The analysis starts by grouping the models into four main groups: G-1, G-2, G-3 and G-4, in which G-1 and G-3 are for SHS keeping the cross-sections used in experimental investigation (80X80X3 and 100X100X4) as references with increasing the thickness of the cross-section for the two groups, G-2 and G-4 are RHS keeping the web length and the thickness constant and change the length of the flange. G-1 and G-2 have nominal $0.2 \%$ proof stress of $700 \mathrm{MPa}$ and G-3 and G-4 have nominal $0.2 \%$ proof stress of $900 \mathrm{MPa}$. Parametric studies are performed by calculating yielding and plastic moment capacity for the cross sections using two different values for strength and elastic modulus. Nominal values for strength and elastic modulus according to equations proposed by European code (EN 1993 1-1) is used in the calculation and compared with actual values obtained from the experimental tests. Table 1 shows the values of elastic moment My, plastic moment Mp and curvature $\kappa$ for actual and nominal values and ultimate moment $\mathrm{Mu}$ capacity obtained from numerical analysis. Curvature at mid-span were calculated for all models using the results obtained from numerical analysis using Eq. (1). Maximum ultimate moment capacity is calculated regarding to the maximum applied load obtained from the numerical analysis. Curvature - moment relationship is performed for all models to obtain maximum and plastic curvature based on the numerical results (see Figure 5). Based on pervious numerical setup, FE analysis is performed for all models to obtain ultimate moment capacity and lateral displacement.

$$
\kappa=\frac{24 \delta_{l / 2}}{3 l^{2}-4 a^{2}},
$$

where: $\kappa-$ curvature, $\delta_{l / 2}-$ mid-span deflection, $l$ - total length, $a-$ Shear span length.

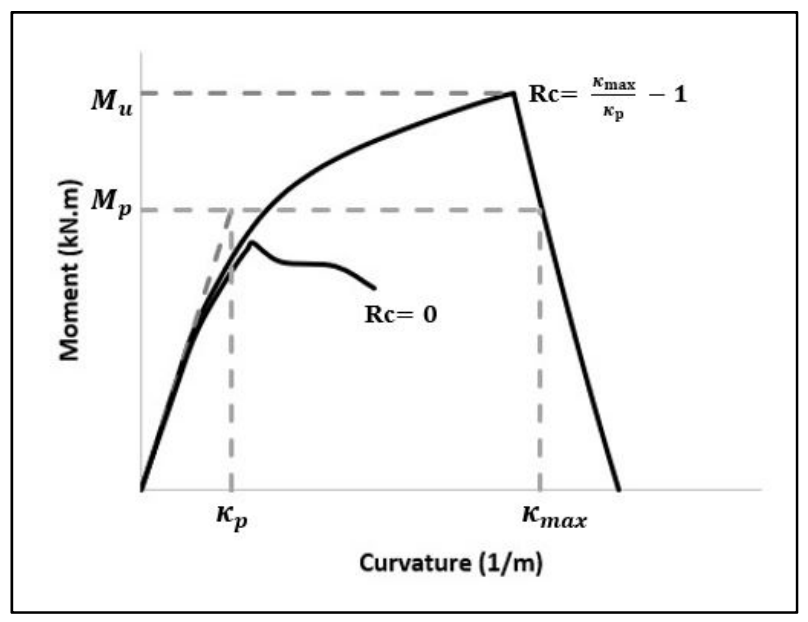

Figure 5. Definition of Curvature capacity

Table 1. Parametric study and FEA results of SHS and RHS

\begin{tabular}{|c|c|c|c|c|c|c|c|c|}
\hline \multirow[b]{2}{*}{ Group } & \multirow[b]{2}{*}{ Sample } & \multicolumn{3}{|c|}{ Nominal values } & \multicolumn{3}{|c|}{ Actual values } & \multirow{2}{*}{$\begin{array}{c}\mathrm{Mu} \\
\text { (kN.m) }\end{array}$} \\
\hline & & $\begin{array}{c}\text { My } \\
(\mathrm{kN} . \mathrm{m})\end{array}$ & $\begin{array}{c}\mathrm{Mp} \\
\text { (kN.m) }\end{array}$ & $\mathrm{Rc}$ & $\begin{array}{c}\text { My } \\
\text { (kN.m) }\end{array}$ & $\begin{array}{c}\mathrm{Mp} \\
\text { (kN.m) }\end{array}$ & $\mathrm{Rc}$ & \\
\hline \multirow{5}{*}{ G-1 } & $80 \times 80 \times 3$ & 15.4 & 18.06 & 0.47 & 17.18 & 20.15 & 0 & 19.5 \\
\hline & $80 X 80 X 4$ & 19.46 & 23.17 & 1.07 & 21.71 & 25.85 & 0 & 25.2 \\
\hline & $80 \times 80 \times 5$ & 23.03 & 27.79 & 1.88 & 25.69 & 31.01 & 1.90 & 32.1 \\
\hline & $80 \times 80 \times 6$ & 26.11 & 32.06 & 3.40 & 29.13 & 35.77 & 3.55 & 32.5 \\
\hline & $80 \times 80 \times 8$ & 29.47 & 37.73 & 3.42 & 32.88 & 42.1 & 3.60 & 46.8 \\
\hline \multirow{4}{*}{ G-2 } & $100 \times 80 \times 3$ & 18.49 & 21.28 & 0.66 & 20.63 & 23.74 & 0 & 22.5 \\
\hline & $120 \times 80 \times 3$ & 21.6 & 24.51 & 1.71 & 24.1 & 27.35 & 1.91 & 34.5 \\
\hline & $140 \times 80 \times 3$ & 24.72 & 27.75 & 3.52 & 27.58 & 30.96 & 3.89 & 57.9 \\
\hline & $160 \times 80 \times 3$ & 27.83 & 30.98 & 3.80 & 31.05 & 34.57 & 4.00 & 67.8 \\
\hline
\end{tabular}


End of Table 1

\begin{tabular}{|c|c|c|c|c|c|c|c|c|}
\hline \multirow[b]{2}{*}{ Group } & \multirow[b]{2}{*}{ Sample } & \multicolumn{3}{|c|}{ Nominal values } & \multicolumn{3}{|c|}{ Actual values } & \multirow{2}{*}{$\begin{array}{c}\mathrm{Mu} \\
(\mathrm{kN} . \mathrm{m})\end{array}$} \\
\hline & & $\begin{array}{c}\text { My } \\
(\mathrm{kN} . \mathrm{m})\end{array}$ & $\begin{array}{c}\mathrm{Mp} \\
(\mathrm{kN} . \mathrm{m})\end{array}$ & $\mathrm{Rc}$ & $\begin{array}{c}\text { My } \\
\text { (kN.m) }\end{array}$ & $\begin{array}{c}\mathrm{Mp} \\
(\mathrm{kN} . \mathrm{m})\end{array}$ & $\mathrm{Rc}$ & \\
\hline \multirow{7}{*}{ G-3 } & $100 \times 100 \times 3$ & 31.86 & 37.08 & 0 & 35.79 & 41.65 & 0 & 30 \\
\hline & $100 X 100 X 4$ & 40.77 & 47.97 & 0 & 45.8 & 53.89 & 0 & 42.56 \\
\hline & $100 \times 100 X 5$ & 48.78 & 58.14 & 0.60 & 54.8 & 65.31 & 0 & 60.6 \\
\hline & $100 \times 100 \times 6$ & 56.07 & 67.59 & 1.29 & 62.99 & 75.93 & 1.45 & 77.1 \\
\hline & $100 \times 100 X 8$ & 65.88 & 81.99 & 2.38 & 74.01 & 92.1 & 2.78 & 94.2 \\
\hline & $100 \times 100 \times 10$ & 73.98 & 94.5 & 1.98 & 83.1 & 106.16 & 2.34 & 106.2 \\
\hline & $100 \times 100 \times 12$ & 73.44 & 99 & 1.56 & 82.5 & 111.21 & 1.88 & 111.26 \\
\hline \multirow{4}{*}{ G-4 } & $120 X 100 X 4$ & 47.39 & 54.88 & 1.08 & 53.23 & 61.65 & 1.22 & 65.4 \\
\hline & $150 \times 100 X 4$ & 57.34 & 65.25 & 2.27 & 64.41 & 73.3 & 2.78 & 102 \\
\hline & $180 X 100 X 4$ & 67.3 & 75.62 & 3.04 & 75.6 & 84.94 & 3.34 & 144 \\
\hline & $200 \times 100 \times 4$ & 73.94 & 82.53 & 3.26 & 83.06 & 92.71 & 3.88 & 172.5 \\
\hline
\end{tabular}

\section{Results and discussion}

Based on the previous results, most of the cross sections exceed its plastic capacity expect two SHS models of G-3 by using nominal values and six models; five SHS models of G-1 and G-3 and one RHS model of G-2 by using actual values. Table 1 shows that two SHS of G-1 and two RHS of G-2 exceeds the rotation capacity limits $(\mathrm{R}=3)$ using nominal values however, one SHS of G-1 and one RHS of G-2 exceeds the rotation capacity limits using actual values.

Rotation capacity against slenderness is performed for all groups to assess the suitability for plastic slenderness limits (see Figure 6a, Figure 6b). In addition, yielding and plastic moment ratio against slenderness parameters is performed for all groups to evaluate these results with limitation of codes (see Figure 7a. Figure 7d). It can be seen from the graphs that plastic flange slenderness limits are applicable for SHS however, these limits are not applicable for RHS for both nominal and actual considerations. On the other hand, plastic web slenderness limits are applicable for all SHS and RHS. Maximum lateral displacement against load is performed using numerical results (red zone in Figure 3) to assess the influence of cross-section aspect ratio on the lateral displacement (see Figure 8a, Figure 8b). The graphs showed that by increasing cross-section aspect ratio from 1 to 2 for those models with yielding strength of $700 \mathrm{MPa}$, the lateral displacement is increased five times for the maximum lateral displacement located directly below the loading point $\mathrm{P}$ with rough contact however, the other lateral displacement point $\mathrm{P}$ with bonded contact is increased by four times with constant load values for both points. Similarly, increasing cross-section aspect ratio from 1 to 2 for those models with yielding strength of $900 \mathrm{MPa}$ increased the lateral displacement by five times for the maximum lateral displacement located directly below the loading point $\mathrm{P}$ with rough contact however, the other lateral displacement point $\mathrm{P}$ with bonded contact is increased by three times with constant load values for both points.

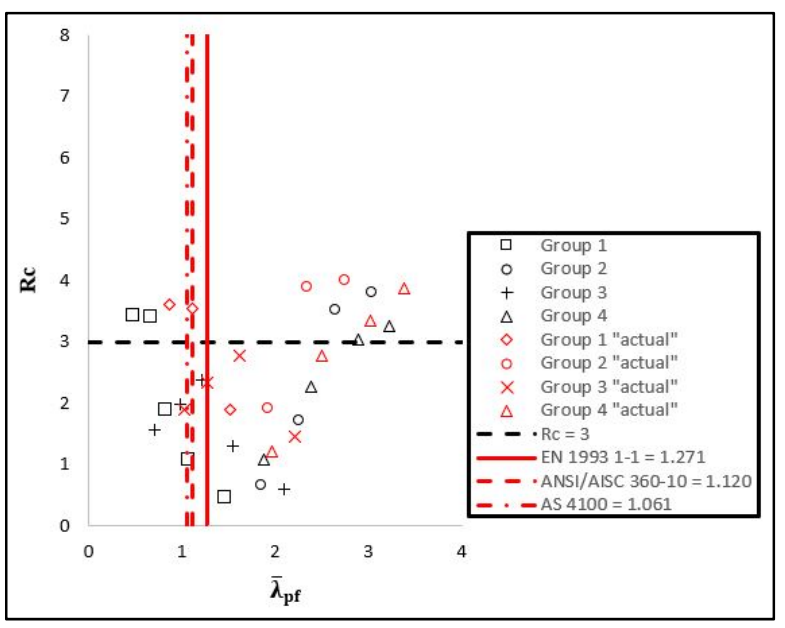

(a) Plastic flange limit

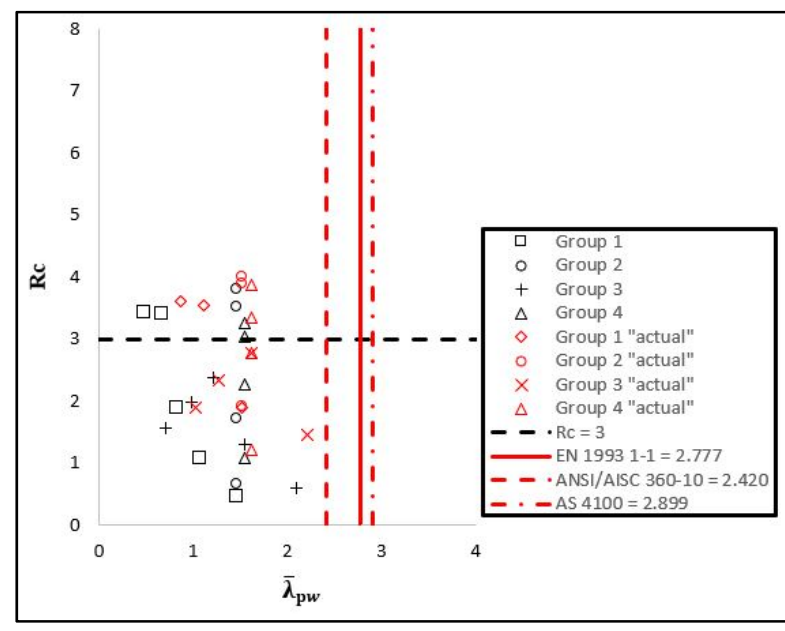

(b) Plastic web limit

Figure 6. Class 1 limit for SHS and RHS 
Adib, S.; Misiunaite, I. 2019. High strength steel cold-formed hollow sections: implication of cross-section aspect ratio and slenderness characteristics on flexural behavior

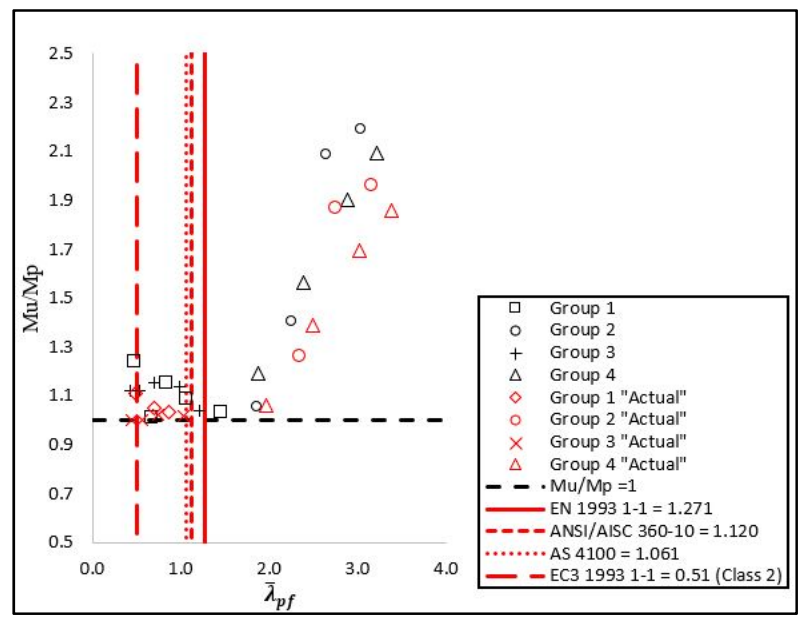

(a) Plastic flange limit

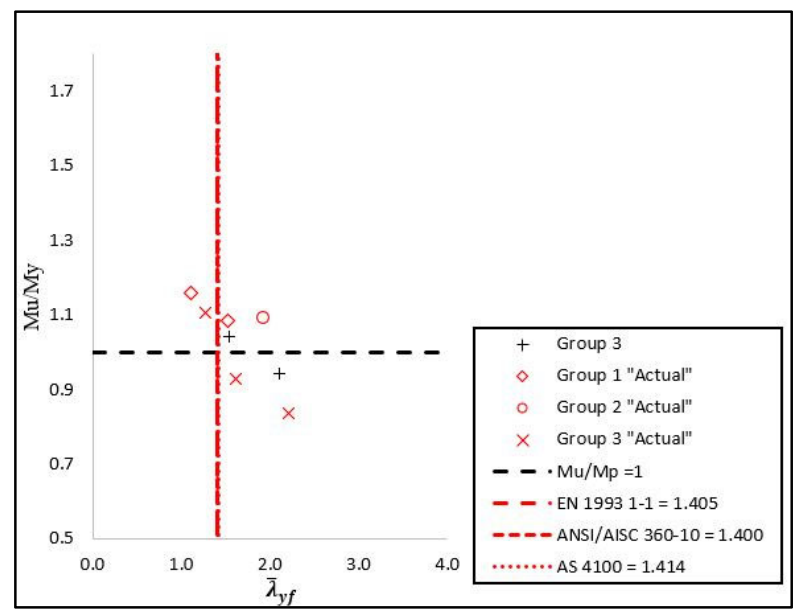

(c) Yield flange limit

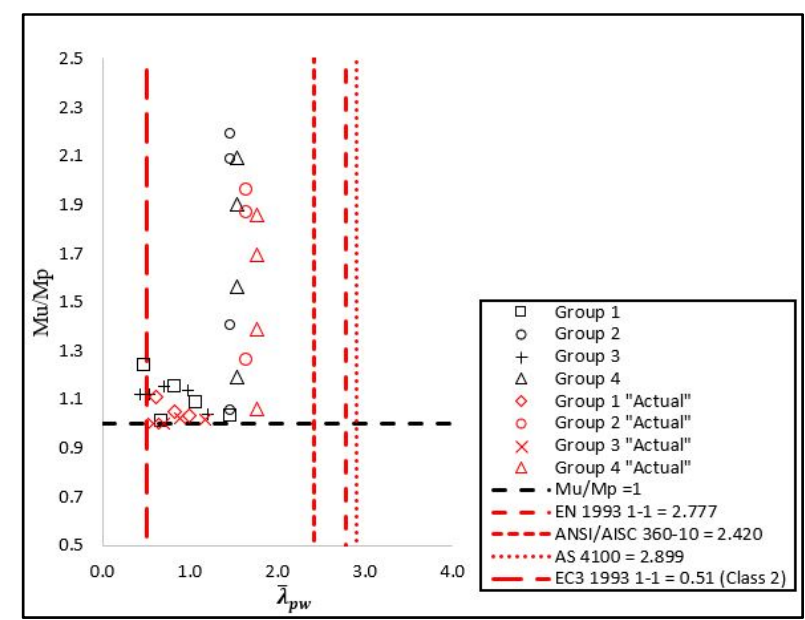

(b) Plastic web limit

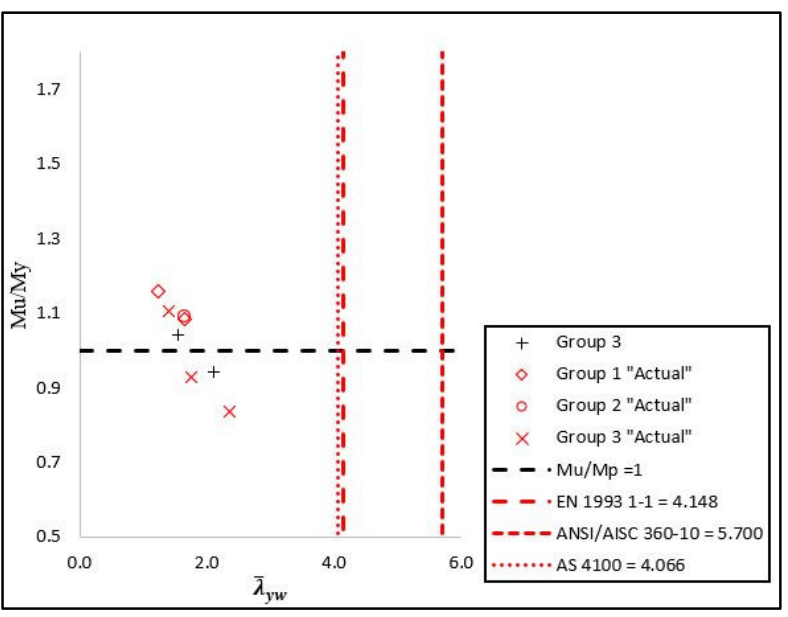

(d) Yield web limit

Figure 7. Plastic and yield slenderness limit for SHS and RHS

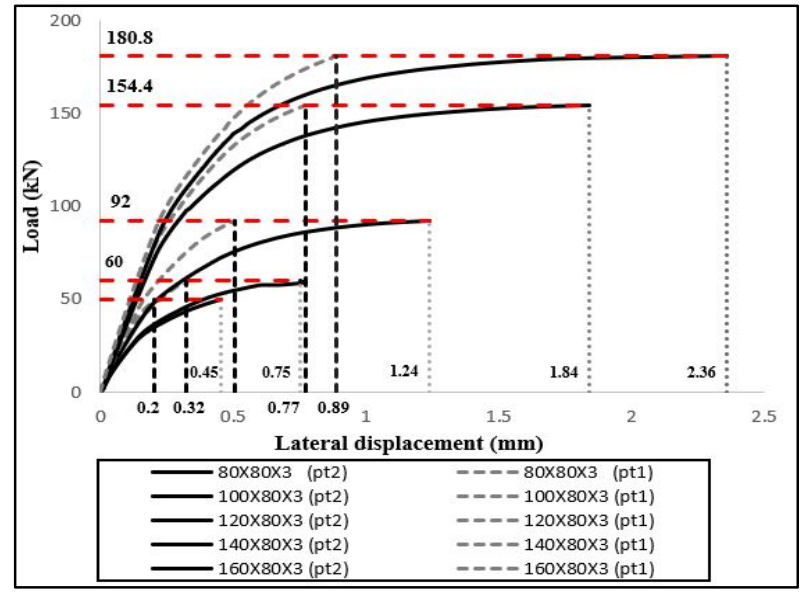

(a) HSS - S700

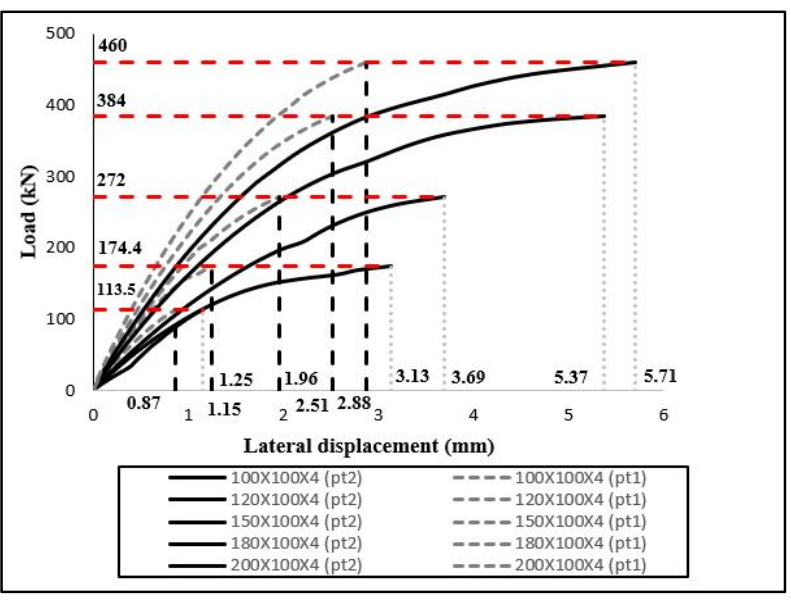

(b) HSS-S900

Figure 8. Lateral displacement - load relationship for RHS 


\section{Conclusions}

In this paper, a numerical modeling investigation for cold-formed high strength steel tubular sections were performed. Upon the validation of finite element analysis, parametric studies were performed over a wide range of cross-section aspect ratio, cross-section slenderness and steel grades. Yield and plastic slenderness limits in different codes were examined against FEA models. The influence of cross section slenderness, cross-section aspect ratio and steel grades on cross-section classification and lateral displacement were examined and compared with codified standards. Based on the test and FEA results, the conclusion can be drawn as follows:

1. The codified plastic flange slenderness limits proposed by EN 1993 1-1, AISC 360-10 and AS 4100 are applicable for SHS however, these limits are not applicable for RHS which has aspect ratio from 1.25 to 2 . On the other hand, codified web slenderness limits are applicable for both SHS and RHS.

2. Increasing cross-section aspect ratio increases the lateral displacements (pt 1 and pt2). Hence, increasing crosssection aspect ratio decreases the interaction between web and flange.

3. Using nominal values of material characteristics is considered more conservative for predicting cross-sections capacities comparing with actual material characteristics.

\section{Acknowledgements}

The authors would like to express their sincere thanks to department of steel and composite structures at Vilnius Gediminas Technical University (VGTU) for their help and supplying test specimens.

\section{References}

American Institute of Steel Construction (AISC). (2016). Specification for structural steel buildings. ANSI/AISC 360-16.

Australian Standard. (1998). Steel structures (AS 4100-1998).

European Committee for Standardization (CEN). (2005). Eurocode 3: Design of steel structures. Part 1-1: General rules and rules for buildings (EN 1993-1-1).

Ma, J., Chan, T., \& Young, B. (2016). Experimental investigation of cold-formed high strength steel tubular beams. Engineering Structure, 126, 200-209. http://dx.doi.org/10.1016/j.engstruct.2016.07.027

Ma, J., Chan, T., \& Young, B. (2017). Design of cold-formed high strength steel tubular beams. Engineering Structure, 151, 432443. http://dx.doi.org/10.1016/j.engstruct.2017.08.002

Yung, X., \& Gardner, L. (2018). The continuous strength method for the design of cold-formed steel non-slender tubular crosssections. Engineering Structure, 175(2018), 549-564. https://doi.org/10.1016/j.engstruct.2018.08.070 